\title{
Turbulence Parameterizations for the Random Displacement Method (RDM) Version of ADPIC
}

\author{
John S. Nasstrom
}

May 1995

This is an informal report intended primarily for internal or limited external distribution. The opinions and conclusions stated are those of the author and may or may not be those of the Laboratory.

This work was performed under the auspices of the Department of Energy by the Lawrence Livermore National Laboratory under Contract W-7405-Eng-48. 


\section{DISCLAIMER}

This document was prepared as an account of work sponsored by an agency of the United States Government. Neither the United States Government nor the University of California nor any of their employees, makes any warranty, express or implied, or assumes any legal liability or responsibility for the accuracy, completeness, or usefulness of any information, apparatus, product, or process disclosed, or represents that its use would not infringe privately owned rights. Reference herein to any specific commercial product, process, or service by trade name, trademark, manufacturer, or otherwise, does not necessarily constitute or imply its endorsement, recommendation, or favoring by the United States Government or the University of California. The views and opinions of authors expressed herein do not necessarily state or reflect those of the United States Government or the University of California, and shall not be used for advertising or product endorsement purposes.

This report has been reproduced directly from the best available copy.

Available to DOE and DOE contractors from the Office of Scientific and Technical Information P.O. Box 62, Oak Ridge, TN 37831

Prices available from (615) 576-8401, FTS 626-8401

Available to the public from the National Technical Information Service

U.S. Department of Commerce 5285 Port Royal Rd., Springfield, VA 22161 


\section{DISCLAIMER}

Portions of this document may be illegible in electronic image products. Images are produced from the best available original document. 


\section{Contents}

Page

1. Introduction

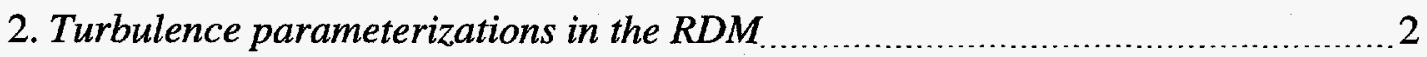

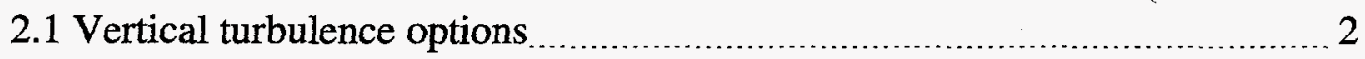

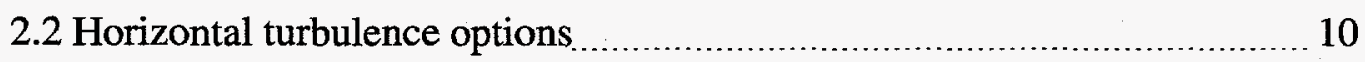

3. Differences between RDM and gradient $A D P I C$

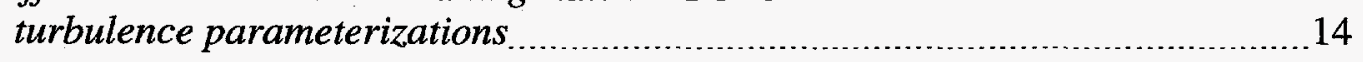

4. Nomenclature

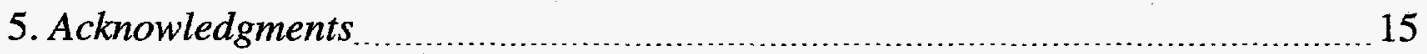

6. References

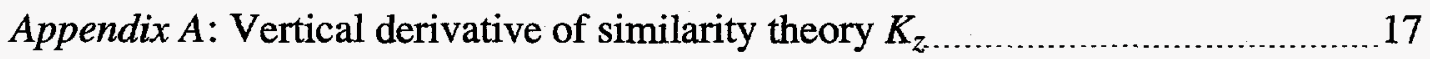

Appendix B: Namelist input parameters for RDM turbulence

parameterizations (and wind speed power law option). 


\section{Introduction}

This document describes the algorithms that are used in the new random displacement method (RDM) option in the ADPIC model to parameterize atmospheric boundary layer turbulence through an eddy diffusivity, $K$. Both the new RDM version and previous gradient version of ADPIC use eddy diffusivities, and, as before, several parameterization options are available. The options used in the RDM are similar to the options for the existing Gradient method in ADPIC (Taylor et al., 1993), but with some changes. Preferred parameterizations are based on boundary layer turbulence scaling parameters and measured turbulent velocity statistics. Simpler parameterizations, based solely on Pasquill stability class, are also available.

When eddy diffusivities are based on boundary layer turbulence scaling parameters (i.e., $u_{*}, h, z$ and $\left.L\right)^{*}$, "turbulence parameterization" is an appropriate term. In other cases, this term is used loosely to describe "sigma curves". These are semi-empirical relationships between the standard deviations, $\sigma_{z}(x)$ and $\sigma_{y}(x)$, of concentration from a point source and downwind distance. Separate sigma curves are used for each of six Pasquill stability classes, which are used to categorize the diffusive properties of the atmospheric surface layer. Consequently, sigma curves are more than parameterizations of turbulence since they also prescribe the final concentration distribution (for a point source) given a Pasquill stability class.

In the ADPIC model, sigma curves can be used to calculate the eddy diffusivities, $K_{z}$ and $K_{H}$. Thus, they can be used to "back out" parameterizations for $K$ which are consistent with the dispersion associated with the particular sigma curve. This results in eddy diffusivities which are spatially homogeneous, but travel time dependent. A vertically homogeneous $K_{z}$ is a poor assumption in the atmospheric boundary layer. A horizontally homogeneous $K_{H}$ is a better assumption because quasi-horizontally-homogeneous turbulence is more common in the atmospheric boundary layer. The use of these timedependent eddy diffusivities is an empirical approach to calculating diffusion at short times when the assumptions implicit in the advection-diffusion equation (on which the RDM is based) are less valid.

An improvement to the overly-broad, site-dependent stability class/sigma curve approach is the use of direct statistical measures of turbulent fluctuations (i.e., $\sigma_{\theta}$ ) along with a horizontal turbulence time scale, $\tau_{H}$, to determine a time-dependent horizontal concentration standard deviation, $\sigma_{y}(t)$. These are used in the RDM as a semi-empirical method of parameterizing a time-dependent, horizontally-homogeneous $K_{H H}$.

\footnotetext{
* See section 4 below for definitions of symbols.
} 
A new feature to the operation of the ADPIC code is that the input parameter "turb_param_type" has been split into two parameters in the RDM option: one which controls the turbulence parameterizations to be used for vertical turbulence (turb_param_vert) and a second which controls the parameterization to be used for horizontal turbulence (turb_param_horz). Another new feature allows the user to override the default values for the constant coefficients used in the turbulence parameterizations.

A major advantage of the RDM over the gradient method is the use of consistent turbulence parameterizations at all times during the calculation. The gradient method required a grid for the diffusion calculation and used turbulence parameterizations for near-in sub-grid diffusion that could be inconsistent with the gradient diffusion portions of the calculation. In addition, unlike the gradient diffusion option, the RDM does not need to approximate travel time using cell-average particle ages for use in time-dependent $K_{\mathrm{H}}$ formulations.

The RDM turbulence parameterization options are described in Section 2. This is followed in Section 3 by a discussion of the differences between the RDM turbulence parameterization options and the old gradient method options. Within the RDM option, improvements and extensions have been made to several parameterizations used in the gradient method option. Two parameterizations used in the gradient diffusion option are not included in the RDM option, because more highly recommended parameterizations are now available.

\section{Turbulence parameterizations in the RDM}

Tables 1 and 2 summarize the options available for both vertical and horizontal turbulence, respectively, in the RDM. An important note is that the new turbulence parameters work only for the RDM, and not in the gradient diffusion option in ADPIC. For the gradient diffusion option the old parameterizations and old input parameters are still used.

\subsection{Vertical turbulence options}

turb param vert = "kz simthry " and " $k z$ simthry user"

These options use $K_{z}$ profiles based on surface layer and boundary layer scaling parameters (Lange, 1989). For the boundary layer $(z<h), K_{z}$ bl is a function of $z, L, h$, and $u_{*}$ as follows:

$$
K_{z}^{\mathrm{bl}}(z)=\frac{k u_{*} z}{\phi_{z}} e^{-c z / h}
$$


Table 1. Vertical turbulence options in the $R D M$

\begin{tabular}{|l|l|}
\hline TURB_PARAM_VERT= & \multicolumn{1}{|c|}{ Description } \\
\hline 'KZ_SIMTHRY' & $\begin{array}{l}K_{z} \text { as a function of } z ; \text { calculated from boundary } \\
\text { layer similarity theory as a function of } u_{*}, h, z \text { and } \\
L \text { for } z<h \text {. Constant, } K_{z}^{\text {tropo }}, \text { used for } z>h .\end{array}$ \\
\hline 'KZ_SIMTHRY_USER' & $\begin{array}{l}K_{z} \text { as a function of } z ; \text { calculated from boundary } \\
\text { layer similarity theory as function of } u_{*}, h, z \text { and } \\
L, \text { but with } u \text { ser-specified coefficients } a, b, \text { and } c .\end{array}$ \\
\hline 'SIGZ_PWRLAWX_PG' & $\begin{array}{l}K_{z} \text { as a function of downwind distance, } x ; \\
\text { calculated from Pasquill-Gifford } \sigma_{z}(x) \text { in a power } \\
\text { law form }\left(\sigma_{z}=\gamma x^{\rho}\right) .\end{array}$ \\
\hline 'SIGZ_PWRLAWX_USER' & $\begin{array}{l}K_{z} \text { as a function of } x \text {; calculated from the power- } \\
\text { law form of } \sigma_{z}=\gamma x^{\rho} \text { and user-specified } \\
\text { coefficients } \gamma \text { and } \rho .\end{array}$ \\
\hline 'KZ_LINEARZ' & $\begin{array}{l}K_{z} \text { calculated from a linear function of height: } \\
K_{z}=K_{\text {zref }}\left(z / z_{\text {ref }}\right), \text { where } K_{z r e f} \text { and } z_{\text {ref }} \text { are } \\
\text { specified by the user. }\end{array}$ \\
\hline 'KZ_CONSTANTZ' & $K_{z}$ fixed at constant value. \\
\hline
\end{tabular}

Table 2. Horizontal turbulence options in the $R D M$

\begin{tabular}{|l|l|}
\hline TURB_PARAM_HORZ $=$ & \multicolumn{1}{|c|}{ Description } \\
\hline 'SIGH_SIGTHETA' & $\begin{array}{l}K_{H} \text { as a function of particle age (time) } t \text {; calculated } \\
\text { from Draxler's } \sigma_{y}(t) \text { using input } \sigma_{\theta} \text { data and } \\
\text { internal-default } \tau_{H}\end{array}$ \\
\hline 'SIGH_SIGTHETA_USER' & $\begin{array}{l}K_{H} \text { as a function of particle age (time) } t \\
\text { calculated from Draxler's } \sigma_{y}(t) \text { using input } \sigma_{\theta} \\
\text { data and user-specified } \tau_{H} .\end{array}$ \\
\hline 'SIGH_PWRLAWX_PG' & $\begin{array}{l}K_{H} \text { as a function of downwind distance } x ; \\
\text { calculated from Pasquill-Gifford } \sigma_{y}(x) \text { in a power } \\
\text { law form }\left(\sigma_{y}=\alpha x^{\beta}\right) .\end{array}$ \\
\hline 'SIGH_PWRLAWX_MESO' & $\begin{array}{l}K_{H} \text { as a function of } x \text {; calculated from MESODIF } \\
\sigma_{y}(x) .\end{array}$ \\
\hline 'SIGH_PWRLAWX_LONGRANGE' & $\begin{array}{l}K_{H} \text { as a function of } x \text {; calculated from Rodriguez's } \\
\text { long-range } \sigma_{y}(x) .\end{array}$ \\
\hline 'SIGH_PWRLAWX_USER' & $\begin{array}{l}K_{H} \text { as function of } x \text {; calculated from power law } \\
\text { form of } \sigma_{y}=\alpha x^{\beta} \text { and } \text { user-specified coefficients } \\
\alpha \text { and } \beta .\end{array}$ \\
\hline
\end{tabular}


where

$$
\begin{gathered}
\phi_{z}=\left(1+a \frac{z}{L}\right)^{b}, \\
a=\left\{\begin{array}{c}
-15, \text { if } 1 / L<0 \\
0, \text { if } 1 / L=0, \\
4.5, \text { if } 1 / L>0
\end{array}\right. \\
b=\left\{\begin{array}{l}
-0.25, \text { if } 1 / L<0 \\
1, \text { if } 1 / L \geq 0
\end{array},\right.
\end{gathered}
$$

and

$$
c=4 \text {. }
$$

These default values for $a, b$, and $c$ can be overridden by user input.

For the free troposphere $(z>h), K_{z}$ is constant with height with a value of

$$
K_{z}=K_{z}{ }^{\text {tropo }} \text {. }
$$

In order to obtain a single $K_{z}$ function for all $z$ which is a smooth, differentiable function of $z$ and which provides a quick transition from $K_{z}$ bl to $K_{z}$ tropo above $z=h$, a function $H(z)$ proposed by Ermak (1994, private communication) is used as follows:

$$
K_{z}=H(z) K_{z}^{\mathrm{bl}}(z)+[1-H(z)] K_{z}^{\mathrm{tropo}},
$$

where

$$
\begin{gathered}
H(z)=e^{-\left(z / c_{2} h\right)^{8}}, \text { and } \\
c_{2}=1.5 .
\end{gathered}
$$

$K_{z}$ tropo may be larger or smaller than the value of $K_{z}$ bl at the mixed layer height, $h$. Therefore, especially under stable conditions, $K_{z}$ may increase with height above $z \approx h$. The user may overide the default value of $K_{z}$ tropo, which is currently $1 \mathrm{~m}^{2} / \mathrm{s}$. Figs. 1-3 show example $K_{z}$ profiles for unstable, neutral and stable cases. Appendix A gives the vertical derivative of $K_{z}$, which is also required by the RDM.

Since this turbulence parameterization uses fundamental boundary layer turbulence scaling parameters and accounts for vertical inhomogeneity of $K_{z}$, it is the preferred option for vertical turbulence parameterization. 


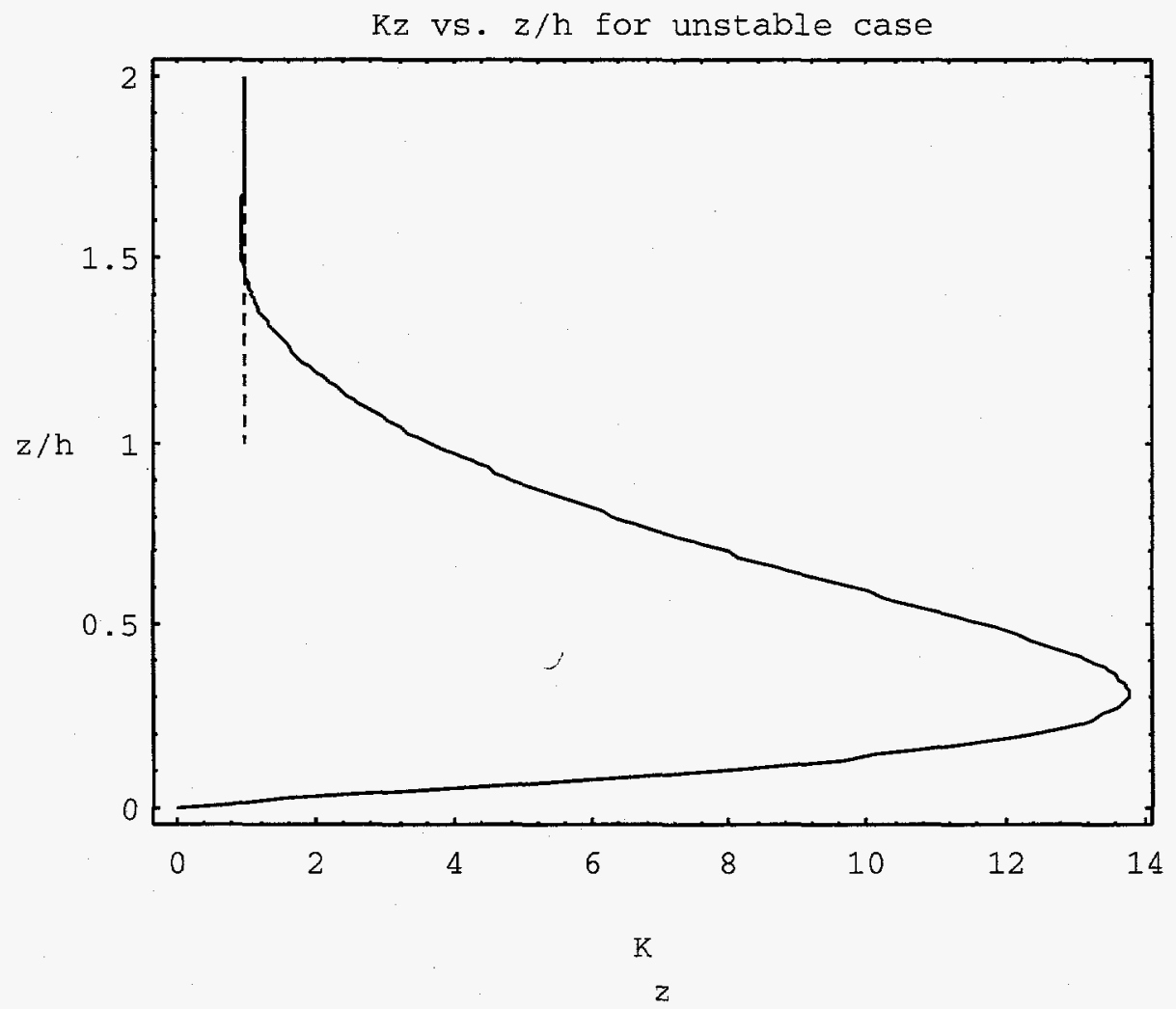

Fig. 1. Example $K_{z}$ profile (solid line) for an unstable case ( $u_{*}=0.3 \mathrm{~m} / \mathrm{s}$, $h / L=-9)$. For reference, dashed line shows $K_{z}^{\text {tropo }}$ value $\left(=1 \mathrm{~m}^{2} / \mathrm{s}\right)$. 


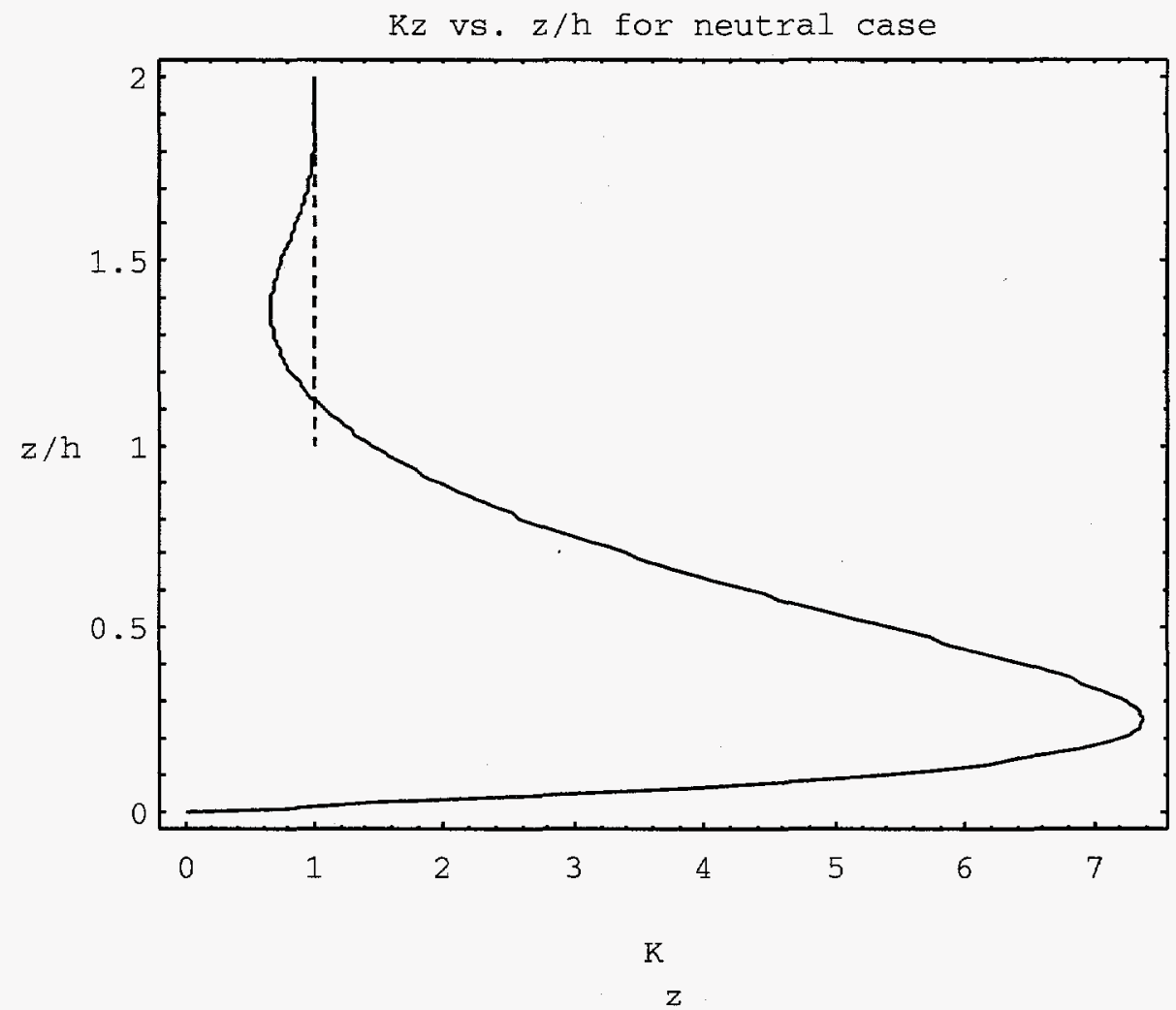

Fig. 2. Example $K_{z}$ profile (solid line) for a neutral stability case ( $u *=0.4$ $\mathrm{m} / \mathrm{s}, h / L=0$.). For reference, dashed line shows $K_{z}$ tropo value $\left(=1 \mathrm{~m}^{2} / \mathrm{s}\right)$. 


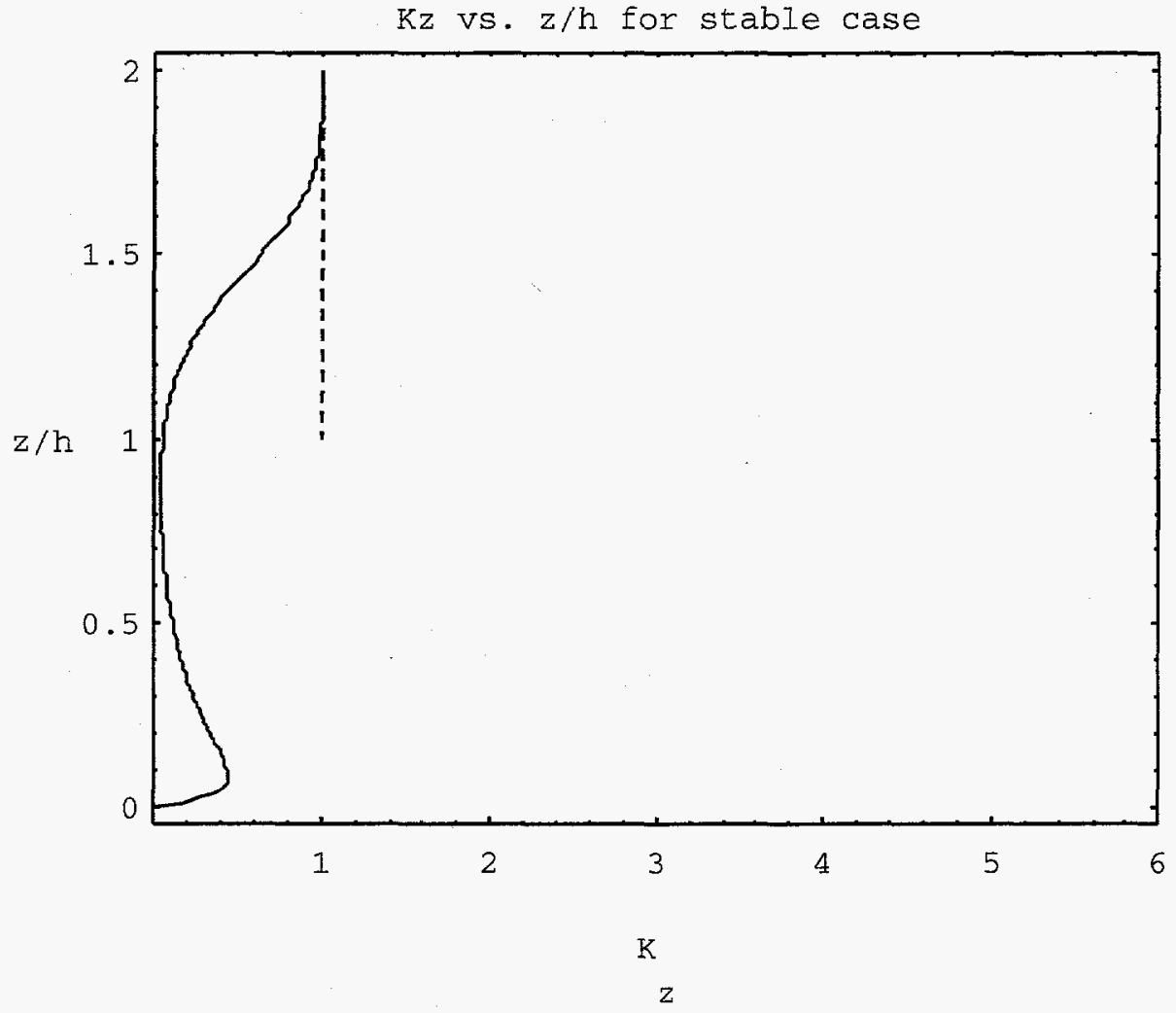

Fig. 3. Example $K_{z}$ profile (solid line) for a stable case ( $u *=0.3 \mathrm{~m} / \mathrm{s}$, $h / L=6)$. For reference, dashed line shows $K_{z}^{\text {tropo }}$ value $\left(=1 \mathrm{~m}^{2} / \mathrm{s}\right)$. 
turb param vert $=$ 'sigz pwrlawx $p g^{\prime}$

In this option $K_{z}$ is determined from Pasquill-Gifford $\sigma_{z}(x)$ using only stability class. $K_{z}$ is calculated from $\sigma_{z}(x)$ in the following form:

$$
\sigma_{z}=\gamma x^{\rho}
$$

There are different coefficients $\gamma$ and $\rho$ for each of six Pasquill stability classes, A, B, C, $\mathrm{D}, \mathrm{E}$, and F, corresponding in the ADPIC code to stab_class $=1,2,3,4,5$ and 6 , respectively. Values for these coefficients were determined by Lange (1993, private communication) by fitting sigma curves developed by Pasquill, adapted by Gifford, and published in Fig. 3.11 of Meteorology and Atomic Energy (Slade, 1968). These curves are based on data from experiments on surface releases with release durations and averaging times of 3-15 min. Therefore, it is recommended for calculations of near-surface sources with release durations, concentration averaging times and wind data temporal resolution close to this 3-15 min time period, and when only stability class is available.

Using the relationship between the variance of the concentration distribution and the eddy diffusivity*,

$$
K=\frac{1}{2} \frac{d \sigma^{2}}{d t}
$$

and the relationship between mean wind speed (assumed to be constant) and downwind distance,

$$
x=\bar{u} t
$$

a relationship for $K_{z}$ can be obtained":

$$
K_{z}=\gamma^{2} \rho \bar{u} x^{(2 \rho-1)} .
$$

Values of the $\gamma$ and $\rho$ coefficients were determined by Lange (1993, private communication) by fitting the close-in portions of the Pasquill-Gifford curves and are as

\footnotetext{
* This relationship assumes $K$ is spatially homogeneous. However, this assumption is not generally valid in the vertical direction in the boundary layer, especially under unstable conditions. Correspondingly, vertical concentration distributions are not Gaussian in the vertical direction, as is assumed in this option.

\# In calculating $K$, the time $t$ is the age of the particle since it was emitted from the source, and $\bar{u}$ is the mean wind at the particle location.
} 
follows:

\begin{tabular}{lcl}
$\begin{array}{l}\text { stab } \\
\text { class }\end{array}$ & $\gamma$ & $\rho$ \\
\hline 1 & 0.013 & 1.5 \\
2 & 0.039 & 1.2 \\
3 & 0.222 & 0.81 \\
4 & 0.382 & 0.64 \\
5 & 0.418 & 0.58 \\
6 & 0.288 & 0.55 \\
\hline
\end{tabular}

A new parameter, $x_{\max }$, specifies the downwind distance beyond which the value of $K_{z}$ is held constant at its value at that maximum distance. The default values are as follows:

\begin{tabular}{lc}
$\begin{array}{l}\text { stab } \\
\text { class }\end{array}$ & $x_{\max }(\mathrm{m})$ \\
\hline 1 & $5 . \mathrm{E}+3$ \\
2 & $1 . \mathrm{E}+4$ \\
3 & $1 . \mathrm{E}+4$ \\
4 & $1 . \mathrm{E}+4$ \\
5 & $1 . \mathrm{E}+4$ \\
6 & $1 . \mathrm{E}+4$ \\
\hline
\end{tabular}

turb param vert $=$ ' $k z$ linearz'

This new option allows $K_{z}$ to be calculated as a function of height from the linear equation:

$$
K_{z}=K_{z \text { ref }}\left(z / z_{\text {ref }}\right)
$$

where $K_{z_{\text {ref }}}$ is the value of $K_{z}$ at reference height $z_{\text {ref }} . K_{z_{\text {ref }}}$ and $z_{\text {ref }}$ must be input by the user, and do not have any internal default values. When used with the wind speed power law option, this linear $K_{z}$ option allows RDM calculations to be compared to analytical solutions to the advection-diffusion equation.

turb param vert $=$ ' $k z$ constantz'

This new option allows $K_{z}$ to be fixed at a constant value, unchanging with height, time or downwind distance:

$$
K_{z}=K_{z \text { constant }}
$$


When used with the constant wind speed option, this constant $K$ option allows RDM calculations to be compared to a Gaussian solution to the advection-diffusion equation.

\subsection{Horizontal turbulence options}

\section{turb param horz='sigh sigtheta' and 'sigh sigtheta user'}

$K_{H}$ for this option is based on Draxler's (1976) semi-empirical relationship for $\sigma_{y}$ as a function of time and the standard deviation of cross-wind velocity component $\left(\sigma_{v}\right)$. Draxler used an equation of the following form for $\sigma_{y}$ :

$$
\sigma_{y}=\sigma_{v} t f\left(t / \tau_{H}\right)
$$

where

$$
f\left(t / \tau_{H}\right)=\frac{1}{1+d\left(t / \tau_{H}\right)^{1 / 2}} .
$$

This formulation results in $\sigma_{y} \propto t$ for $t<<\tau_{H}$ and $\sigma_{y} \propto t t^{1 / 2}$ for $t \gg \tau_{H}$. The constant $d$ is a combination of constants used by Draxler. A value of $d=0.36$ resulted in Draxler's best fit to close-in diffusion data, and is similar to the value of 0.4 recommended by Hanna et al. (1982). Assuming $d=0.36$, Draxler recommended values of $\tau_{H}=50 \mathrm{sec}$ for surface releases and $160 \mathrm{sec}$ for elevated releases (note: Draxler's $T_{i}$ is equal to $6.36 \tau_{H}$ ). The default values in the RDM are

$$
\begin{gathered}
d=0.36 \text { and } \\
\tau_{H}=50 \mathrm{sec} .
\end{gathered}
$$

The value of $\tau_{H}$ can be overridden by user input. Using eq. (7), assuming $K_{H}=K_{y}$, and using the approximation $\sigma_{v} \approx \sigma_{\theta} \bar{u}$, the following equation for $K_{H}$ can be derived:

$$
K_{H}=\frac{\bar{u}^{2} \sigma_{\theta}{ }^{2} t\left[1+\frac{d}{2}\left(\frac{t}{\tau_{H}}\right)^{1 / 2}\right]}{\left[1+d\left(\frac{t}{\tau_{H}}\right)^{1 / 2}\right]^{3}} .
$$

(Note: $\sigma_{\theta}$ is in radians). 
Since this turbulence parameterization uses measured wind direction fluctuations, it is the preferred option for horizontal turbulence parameterization.

turb param horz='sigh pwrlawx pg', 'sigh pwrlawx meso'. 'sigh pwrlawx longrange'. and 'sigh pwrlawx user',

For these options, $K_{H}$ is based only on stability class and is calculated using $\sigma_{y}(x)$ in the following form:

$$
\sigma_{y}=\alpha x^{\beta}
$$

Using eqs. (7) and (8), and assuming again that $K_{H}=K_{y}$, the following relationship for $K_{H}$ can be obtained:

$$
K_{H}=\alpha^{2} \beta \bar{u} x^{(2 \beta-1)} .
$$

For values of $x \geq x_{\max }$, the value of $K_{H}$ is held constant at its value at that maximum distance.

The constants $\alpha$ and $\beta$ depend on the turb_param_horz option used and are described below:

$\alpha$ and $\beta$ for turb_param_horz $=$ 'sigh_pwrlawx $\_g$ ':

The $\alpha$ and $\beta$ coefficients for $\sigma_{y}(x)$ used in this option are based on a least-squares fit (Lange, 1993, private communication) to the sigma curves developed by Pasquill, adapted by Gifford, and published in Fig. 3.10 of Meteorology and Atomic Energy (Slade, 1968). These curves are based on data from experiments involving surface releases with release durations and averaging times of 3-15 $\mathrm{min}$. Therefore, this turbulence parameterization option is recommended for calculations of near-surface releases with release durations, concentration averaging times and wind data temporal resolution close to this $3-15 \mathrm{~min}$ time period, and when only stability class is available.

There are separate curves for each of six Pasquill stability classes (A, B, C, D, E, and $\mathrm{F}$, corresponding to stab_class $=1,2,3,4,5$ and 6 , respectively). The $\sigma_{y}(x)$ equation coefficients for this option are

$$
\beta=0.92 \text { and }
$$


$\alpha$, depending on stability class, as follows:

\begin{tabular}{lc}
$\begin{array}{lc}\text { stab } \\
\text { class }\end{array}$ & $\begin{array}{c}\text { Pasquill-Gifford } \\
\alpha\end{array}$ \\
\hline 1 & 0.42 \\
2 & 0.30 \\
3 & 0.22 \\
4 & 0.15 \\
5 & 0.09 \\
6 & 0.06 \\
\hline
\end{tabular}

Default values of $x_{\max }$ for this option are as follows:

\begin{tabular}{lc}
$\begin{array}{l}\text { stab } \\
\text { class }\end{array}$ & $\begin{array}{c}\text { Pasquill-Gifford } \\
x_{\max }(\mathrm{m})\end{array}$ \\
\hline 1 & $2 . \mathrm{E}+4$ \\
2 & $2 . \mathrm{E}+4$ \\
3 & $2 . \mathrm{E}+4$ \\
4 & $2 . \mathrm{E}+4$ \\
5 & $2 . \mathrm{E}+4$ \\
6 & $2 . \mathrm{E}+4$ \\
\hline
\end{tabular}

$\alpha$ and $\beta$ for turb_param_horz = 'sigh_pwrlawx_meso':

The equations for $\sigma_{y}(x)$ in this parameterization option are based on a fit to experimental data from near-surface releases from the Idaho National Reactor Testing Station (NRTS) (Yanskey et al., 1966) which were subsequently used in the MESODIF model (Start and Wendell, 1974) for the NRTS. These data show increased horizontal diffusion when compared to the Pasquill-Gifford values above, especially under stable conditions. This is due to both (a) the longer release durations (and, therefore, longer averaging times) used in the NRTS data (15-60 min) compared to the release durations in the Pasquill-Gifford data (3-15 min), and (b) the presence of meandering conditions during stable conditions. Therefore, this option is recommended for calculations of near-surface releases with release durations, concentration averaging times and wind data temporal resolution close to this 15-60 min time period, and when when only stability class is available. The $\sigma_{y}(x)$ equation coefficient values are

$$
\beta=0.85 \text { and }
$$


$\alpha$, depending on stability class, as follows:

\begin{tabular}{lc}
$\begin{array}{l}\text { stab } \\
\text { class }\end{array}$ & $\begin{array}{c}\text { MESODIF } \\
\alpha\end{array}$ \\
\hline 1 & 0.72 \\
2 & 0.42 \\
3 & 0.35 \\
4 & 0.27 \\
5 & 0.30 \\
6 & 0.40 \\
\hline
\end{tabular}

Default values of $x_{\max }$ for this parameterization are as follows:

\begin{tabular}{lc}
$\begin{array}{l}\text { stab } \\
\text { class }\end{array}$ & $\begin{array}{l}\text { MESODIF } \\
x_{\max }(\mathrm{m})\end{array}$ \\
\hline 1 & $2 . \mathrm{E}+4$ \\
2 & $2 . \mathrm{E}+4$ \\
3 & $2 . \mathrm{E}+4$ \\
4 & $2 . \mathrm{E}+4$ \\
5 & $2 . \mathrm{E}+4$ \\
6 & $2 . \mathrm{E}+4$ \\
\hline
\end{tabular}

$\alpha$ and $\beta$ for turb_param_horz = 'sigh_pwrlawx_longrange':

In this option, the equations for $\sigma_{y}(x)$ are based on a fit by Rodriguez et al. (1995) to long-range dispersion data. The $\sigma_{y}(x)$ equation coefficient values are

$$
\begin{array}{ll}
\beta & =1.0, \\
\alpha & =0.056, \text { and } \\
x_{\max } & =4 . E+7 \mathrm{~m}
\end{array}
$$

The large default value of $40,000 \mathrm{~km}$ for $x_{\max }$ is used to assure that these $\alpha$ and $\beta$ coefficients are, for practical purposes, always used, and, therefore, $\sigma_{y} \propto t$ essentially for all time. This parameterization reflects the effect of processes other than turbulent diffusion, i.e., spatial and temporal variation in the mean wind. Therefore, this parameterization is recommend for large-scale calculations using wind fields with low spatial resolution (in particular, low vertical resolution so that vertical wind shear in the lowest kilometer is unresolved) and/or low temporal resolution (e.g., 12 hour resolution). 


\section{Differences between RDM and gradient}

\section{ADPIC turbulence parameterizations}

The RDM turbulence parameterization options reflect some of the significant differences between the RDM and the gradient diffusion method. In the gradient diffusion option in ADPIC one parameter, turb_param_type, controls the turbulence parameterization for 4 distinct parts of the calculation: (1) vertical turbulence for sub-grid diffusion, (2) horizontal turbulence for sub-grid diffusion, (3) vertical turbulence for gradient diffusion, and (4) horizontal turbulence for gradient diffusion. As mentioned above, in the RDM there is no need for a separate method of calculating sub-grid diffusion, and, in addition, the flexibility of controlling the parameterization of vertical and horizontal turbulence separately has been included. Discussed below are differences between the parameterizations used by the RDM and gradient diffusion methods in ADPIC.

One option for gradient diffusion turbulence parameterization that was not included in the $\mathrm{RDM}$ is the gradient diffusion vertical turbulence parameterization used when turb_param_type $=1$ or 2 . This parameterization was based on a more complicated second-order polynomial fit to the Pasquill-Gifford $\sigma_{z}(x)$ curves, and had potentially erroneous behavior, i.e., negative $K_{z}$ and $K_{z}$ decreasing with time for certain stability classes at short or long times.

The second option for gradient diffusion method turbulence parameterization that was not included in the RDM is the gradient diffusion horizontal turbulence parameterization used when turb_param_type $=5$. This option was based on similarity theory for relative diffusion of puffs using the turbulent kinetic energy dissipation rate, $\varepsilon$, as the key turbulence parameter. This option was not included in the RDM because the recommended option based on measured or defaulted sigma theta values is now readily usable.

The gradient diffusion vertical turbulence parameterization based on similarity theory and used when turb_param_type $=4$ or 5 has been modified for use in the RDM. The formulation for $K_{z}$ has been restored to the form in the referenced journal articles. In addition it now uses a single formulation for the surface layer and outer boundary layer and, correspondingly, has a continuous first derivative with respect to height. The new formulation used by the RDM corrects some problems with low values of $K_{z}$ above the surface layer in unstable condtions.

The gradient diffusion horizontal turbulence parameterization based on $\sigma_{\theta}$ and used when turb_param_type $=4$ or 5 has been modified for use in the RDM. This parameterization no longer uses an approximation to Draxler's (1976) expression; it now uses the exact expression. 
The gradient diffusion horizontal turbulence parameterization based on a power law form for $\sigma_{y}(x)$ and used when turb_param_type $=1$ or 2 and hemi_scale $=$ ' $y$ ' used a constant $K_{H}$ (with a value dependent on stability class) beyond $20 \mathrm{~km}$ downwind distance. For this long-range diffusion parameterization, the RDM (by default) uses a $K_{H}$ that is a linear function of travel distance for all distances of interest.

\section{Nomenclature}

$\begin{array}{ll}h & \text { mixed layer height }(\mathrm{m}) \\ k & \text { von Karman constant }(=0.4) \\ K_{x} & \text { along-wind eddy diffusivity }\left(\mathrm{m}^{2} / \mathrm{s}\right) \\ K_{y} & \text { cross-wind eddy diffusivity }\left(\mathrm{m}^{2} / \mathrm{s}\right) \\ K_{z} & \text { vertical eddy diffusivity }\left(\mathrm{m}^{2} / \mathrm{s}\right) \\ K_{H} & \left.\text { horizontal eddy diffusivity }\left(\mathrm{m}^{2} / \mathrm{s}\right) \text { (Note: It is assumed that } K_{H}=K_{x}=K_{y}\right) \\ L & \text { Obukhov length }(\mathrm{m}) \\ t & \text { particle age; time since material released (s). } \\ \bar{u} & \text { mean wind speed }(\mathrm{m} / \mathrm{s}) \\ u_{*} & \text { friction velocity }(\mathrm{m} / \mathrm{s}) \\ x & \text { downwind travel distance }(\mathrm{m}) \text { (Note: This is approximated as } \bar{u} t) \\ y & \text { crosswind distance }(\mathrm{m}) \\ z & \text { height above ground level (m) } \\ \sigma_{H} & \text { horizontal standard deviation of spatial distribution of concentration }(\mathrm{m}) \\ \sigma_{y} & \left.\text { (Note: It is assumed that } \sigma_{y}=\sigma_{x}=\sigma_{H}\right) \\ \sigma_{z} & \text { crosswind standard deviation of spatial distribution of concentration }(\mathrm{m}) \\ \sigma_{\theta} & \text { vertical standard deviation of spatial distribution of concentration }(\mathrm{m}) \\ \sigma_{v} & \text { standard deviation of wind direction (radians) } \\ \tau_{H} & \text { standard deviation of cross-wind speed component }(\mathrm{m} / \mathrm{s})\end{array}$

\section{Acknowledgments}

In completing this work, the author benefited greatly from discussion with and work by Don Ermak, Rolf Lange, Allan Taylor, Howard Rodean, Dan Rodriguez, Bob Freis, and Jim Ellis. This work was performed under the auspices of the U.S. Department of Energy by Lawrence Livermore National Laboratory under contract number W-7405-Eng-48 and by EG\&G Energy Measurements, Inc. under contract number DE-AC08-93NV11265. 


\section{References}

Draxler, R.R. (1976) Determination of atmospheric diffusion parameters, Atmos. Environ., 10, 99-105.

Hanna S.R., G.A. Briggs, and R.P. Hosker, Jr. (1982) Handbook on atmospheric diffusion, DOE/TIC-11223, U.S. Dept. of Energy, 102 pp..

Lange, R. (1985) Relationship between model complexity and data base quality for complex terrain tracer experiments, Ph.D. Dissertation, University of California, Davis, CA, 140 pp..

Lange, R. (1989) Transferability of a Three-Dimensional Air Quality Model between Two Different Sites in Complex Terrain, J. Appl. Meteorol., 28, 7, pp. 665-679

Taylor, A.G., et al. (eds.), (1993) User's Guide to the MATHEW/ADPIC Models, UCRLMA-103581, LLNL, Livermore, CA.

Rodriguez, D.J., H. Walker, N. Klepikova, A. Kostrikov, and Y. Zhuk (1995) Evaluation of two pollutant dispersion models over continental scales, Atmos. Environ., 29, 799812. Also UCRL-JC-115003, LLNL, Livermore, CA.

Slade, D.H. (ed.) (1968) Meteorology and Atomic Energy, U.S. Atomic Energy Commission (Available from NTIS, Springfield, VA as TID-24190)

Start, G.T. and L.L. Wendell (1974) Regional Effluent Dispersion Calculations Considering Spatial and Temporal Meteorological Variations, NOAA Tech. Memo. ERL ARL-44, Air Resources Lab., Idaho Falls, Idaho (Available from NTIS, Springfield, VA)

Yanskey, G.R., E.H. Markee, Jr., and A.P. Richter (1966) Climatography of the National Reactor Testing Station, IDO-12048, Air Resources Field Research Office, National Reactor Testing Station, Idaho Falls, Idaho. (Available from NTIS, Springfield, VA) 
Appendix A: Vertical derivative of similarity theory $K_{z}$

$$
\frac{\partial K_{z}}{\partial z}=H(z) \frac{\partial K_{z}^{\mathrm{bl}}}{\partial z}+K_{z}^{\mathrm{bl}}(z) \frac{\partial H(z)}{\partial z}-K_{z}^{\text {tropo }} \frac{\partial H(z)}{\partial z}
$$

where

$$
\begin{gathered}
H(z)=e^{-\left(z / c_{2} h\right)^{8}}, \\
\frac{\partial H(z)}{\partial z}=\frac{-8 z^{7}}{\left(c_{2} h\right)^{8}} H(z), \\
\frac{\partial K_{z}^{\mathrm{bl}}}{\partial z}=\frac{k u_{*}}{\phi_{z}} e^{-c z / h}\left(1-\frac{c z}{h}-\frac{z}{\phi_{z}} \frac{\partial \phi_{z}}{\partial z}\right), \text { and } \\
\frac{\partial \phi_{z}}{\partial z}=\frac{a b}{L}\left(1+a \frac{z}{L}\right)^{b-1} .
\end{gathered}
$$




\section{Appendix B: \\ Namelist input parameters for \\ RDM turbulence parameterizations \\ (and wind speed power law option)}

NOTE: Namelist parameters controlling the RDM numerical calculation and time step are not listed below. See UCRL-ID, "Implementation of a Random Displacement Method (RDM) in the ADPIC Model Framework", Appendix II, by Ermak et al. for descriptions of these namelist input parameters.

\section{ADPIC_CONTROL namelist}

\section{DIFF METHOD}

New option:

DIFF_METHOD = 'RDM'

Diffusion is calculated with the Random Displacement Method (RDM). For this method, the types of horizontal and vertical turbulence parameterizations to be used for $K_{z}$ and $K_{H}$ respectively, by the RDM must be specified using the parameters TURB_PARAM_VERT and TURB_PARAM_HORZ.

\section{REFLECT AT MLHGT}

A character variable (' $y$ ' / $n$ ') which selects whether or not a particle reflection algorithm at the mixing layer height, mlhgt, is to be used. If selected, a particle approaching the mixing layer height from below will be reflected downward if the computed motion would otherwise take the particle above the mixing layer height. Particles approaching from above the mixing layer height are not affected until their motion drops them below the mixing layer height.Then, such a particle is treated as if it had been created below the mixing layer height. With this algorithm in effect, a particle can only be above the mixing layer height if it was released there. (Default: ' $y$ '). Note: This parameter used only with DIFF_METHOD = 'RDM'.

\section{WIND TYPE}

New option:

'POWER_LAW'

Produces a vertical power law wind field in ADPIC which is purely analytical and not gridded. No input wind field files are needed for this option. Power law winds are controlled by input parameters U_MEAN_REF, U_MEAN_REF_HGT, PWRLAW_EXPNT_U, and U_MEAN_DIR, which must be entered for this option. 
Winds vary with power law in the vertical, but do not vary in the horizontal directions at any given height.

WARNING: Use only with with flat terrain.

\section{ADPIC_METPARAMS namelist}

\section{TURB PARAM VERT}

Character string identifying vertical turbulence parameterization option to be used. The parameter applies only if DIFF_METHOD = 'RDM' in the ADPIC_CONTROL namelist. Possible values are as follows:

TURB_PARAM_VERT = 'KZ_SIMTHRY'

$K_{z}$ as function of $z$ calculated from boundary layer similarity theory as function

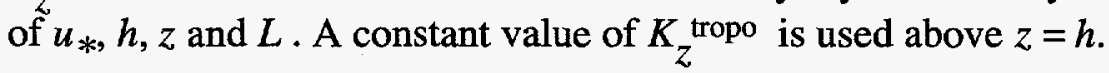

TURB_PARAM_VERT= 'KZ_SIMTHRY_USER'

$K_{z}(z)$ as function of $z$ calculated from boundary layer similarity theory as function of $u_{*}, h, z$ and $L$, but with user-specified coefficients $a, b, c$, and $K_{z}$ (tropo (KZ_SIMTHRY_PHI_A, KZ_SIMTHRY_PHI_B, KZ_SIMTHRY_C, and KZ_SIMTHRY_TROPO)

TURB_PARAM_VERT= 'SIGZ_PWRLAWX_PG'

$K_{z}$ as function of downwind distance, $x$, calculated from Pasquill-Gifford $\sigma_{z}(x)$ in a power law form.

TURB_PARAM_VERT = 'SIGZ_PWRLAWX_USER'

$K_{z}$ as function of downwind distance $x$ (in meters) calculated from $\sigma_{z}(x)$ (in meters) using user-specified power law coefficients $\gamma$ and $\rho$ (SIGZ_PWRLAWX_GAMMA and SIGZ_PWRLAWX_RHO) in the power law equation: $\sigma_{z}=\gamma x^{\rho}$.

TURB_PARAM_VERT $=$ 'KZ_LINEARZ'

$K_{z}$ calculated from power law equation, $K_{z}=K_{z \text { ref }}\left(z / z_{\text {ref }}\right)$, where $K_{z r e f}$ and $z_{\text {ref }}$. (KZ_LINEARZ_REF and KZ_LINEARZ_REF_HGT) are specified by the user.

TURB_PARAM_VERT $=$ 'KZ_CONSTANTZ'

$K_{Z}$ fixed at constant value $=\mathrm{KZ} Z_{-}$CONSTANTZ, specified by the user. 


\section{TURB PARAM HORZ}

Character string identifying horizontal turbulence parameterization option to be used. This parameter applies only if DIFF_METHOD = 'RDM'. Possible values are as follows:

TURB_PARAM_HORZ = 'SIGH_SIGTHETA'

$K_{H}$ as function of $t$ calculated from Draxler $\sigma_{y}(t)$ using input $\sigma_{\theta}$ data (see SIGMA_THETA_DATA namelist) and internal-default value of HORZ_TIME_SCALE, $\tau_{H}$.

TURB_PARAM_HORZ = 'SIGH_SIGTHETA_USER'

$K_{H}$ as function of $t$ calculated from Draxler $\sigma_{y}(t)$ using input $\sigma_{\theta}$ data (see SIGMA_THETA_DATA namelist) and user-input value of HORZ_TIME_SCALE, $\tau_{H}$.

TURB_PARAM_HORZ = 'SIGH_PWRLAWX_PG'

$K_{H}$ as function of downwind distance $x$ calculated from Pasquill-Gifford $\sigma_{y}(x)$ in a power law form $\left(\sigma_{H}=\sigma_{y}=\alpha x^{\beta}\right)$

TURB_PARAM_HORZ = 'SIGH_PWRLAWX_MESO'

$K_{H}$ as function of downwind distance $x$ calculated from MESODIF $\sigma_{y}(x)$

TURB_PARAM_HORZ = 'SIGH_PWRLAWX_LONGRANGE'

$K_{H}$ as function of downwind distance $x$ calculated from Dan Rodriguez's long-range $\sigma_{y}(x)$

TURB_PARAM_HORZ = 'SIGH_PWRLAWX_USER'

$K_{H}$ as function of downwind distance $x$ (in meters) calculated from $\sigma_{y}(x)$ (in meters) using user-specified power law coefficients SIGH_PWRLAWX_ALPHA, $\alpha$, and SIGH_PWRLAWX_BETA, $\beta$ in the power equation: $\sigma_{H}=\alpha x^{\beta}$.

HORZ TIME SCALE

Horizontal turbulence time scale, $\tau_{H}$ (seconds). Applies to TURB_PARAM_VERT $=$ 'KH_SIGTHETA_USER' option only, and must be input for that option.

(Default: $50 \mathrm{~s}$ for TURB_PARAM_VERT = 'KH_SIGTHETA' )

\section{K VON KARMAN}

Optional input parameter to override default value of the von Karman constant, $k$.

(Default: K_VON_KARMAN $=0.4$ )

\section{KZ CONSTANTZ}

Constant $K_{z}$ value used when TURB_PARAM_VERT= 'KZ_CONSTANTZ'. Must be input by the user. No internal default value. 
KZ LINEARZ REF

Reference value $K_{z r e f}\left(\mathrm{~m}^{2} / \mathrm{s}\right)$ for linear vertical eddy diffusivity profile, $K_{z}=K_{z \text { ref }}\left(z / z_{\text {ref }}\right)$. Applies to TURB_PARAM_VERT $=$ 'KZ_LINEARZ' option only, and must be input for that option.

KZ LINEARZ REF HGT

Reference height $z_{\text {ref }}(\mathrm{m})$ for power law vertical eddy diffusivity reference value. Applies to TURB_PARAM_VERT = 'KZ_LINEARZ' only, and must be input for that option.

\section{KZ SIMTHRY PHI A}

Constant, $a$, for similarity theory vertical eddy diffusivity profile phi function. Applies to TURB_PARAM_VERT = 'KZ_SIMTHRY_USER' option only, and must be input for that option.

\section{KZ SIMTHRY PHI B}

Constant, $b$, for similarity theory vertical eddy diffusivity profile phi function. Applies to TURB_PARAM_VERT = 'KZ_SIMT.HRY_USER' option only, and must be input for that option.

\section{KZ SIMTHRY C}

Constant, $c$, for similarity theory vertical eddy diffusivity profile. Applies to TURB_PARAM_VERT = 'KZ_SIMTHRY_USER' option only, and must be input for that option.

\section{KZ SIMTHRY TROPO}

Constant value of $K_{z}^{\text {tropo }}$ used above $z>h$. when TURB_PARAM_VERT= 'KZ_SIMTHRY_USER'.

\section{SIGH PWRLAWX ALPHA}

Constant $\alpha$ in power-law equation for horizontal concentration standard deviation versus downwind distance, $\sigma_{H}=\alpha x^{\beta}$, used to calculate horizontal eddy diffusivity. Applies to TURB_PARAM_HORZ = 'SIGH_PWRLAWX_USER' option only, and must be input for that option.

\section{SIGH PWRLAWX BETA}

Constant $\beta$ in power-law equation for horizontal concentration standard deviation versus downwind distance, $\sigma_{H}=\alpha x^{\beta}$, used to calculate horizontal eddy diffusivity. Applies to TURB_PARAM_HORZ = 'SIGH_PWRLAWX_USER' option only, and must be input for that option.

\section{SIGH PWRLAWX XMAX}

Maximum downwind distance which the power law equation for horizontal concentration standard deviation versus downwind distance is to be used. After this distance the value of horizontal diffusivity, $K_{H}$, is held constant at its value at this distance. Applies to 
TURB_PARAM_HORZ = 'SIGH_PWRLAWX_USER' option only, and must be input for that option.

\section{SIGZ PWRLAWX GAMMA}

Constant $\gamma$ in power-law equation for vertical concentration standard deviation versus downwind distance, $\sigma_{z}=\gamma x^{\rho}$, used to calculate vertical eddy diffusivity. Applies to TURB_PARAM_VERT = 'SIGZ_PWRLAWX_USER' option only, and must be input for that option.

\section{SIGZ PWRLAWX RHO}

Constant $\rho$ in power-law equation for vertical concentration standard deviation versus downwind distance, $\sigma_{z}=\gamma x^{\rho}$, used to calculate vertical eddy diffusivity. Applies to TURB_PARAM_VERT = 'SIGZ_PWRLAWX_USER' option only, and must be input for that option.

\section{SIGZ PWRLAWX XMAX}

Maximum downwind distance $(\mathrm{m})$ which the power law equation for vertical concentration standard deviation versus downwind distance is to be used. After this distance the value of vertical diffusivity, $K_{z}$, is held constant at its value at this distance. Applies to TURB_PARAM_HORZ = 'SIGH_PWRLAWX_USER' option only, and must be input for that option.

\section{U MEAN REF}

Reference wind speed value $\bar{u}_{1}(\mathrm{~m} / \mathrm{s})$ for power law wind profile:

$$
\bar{u}(z)=\bar{u}_{1}\left(\frac{z}{z_{1}}\right)^{m} .
$$

Applies to WIND_TYPE= 'POWER_LAW' option only, and must be input for that option.

\section{PWRLAW EXPNT U}

Exponent $m$ for power law wind profile. Applies to WIND_TYPE= 'POWER_LAW' option only, and must be input for that option.

\section{U MEAN REF HGT}

Reference height $z_{1}(\mathrm{~m})$ for power law wind profile reference wind speed, U_MEAN_REF. Applies to WIND_TYPE= 'POWER_LAW' option only, and must be input for that option.

\section{U MEAN DIR}

Mean horizontal wind direction (in degrees) using standard meteorolgical convention (clockwise from north for direction wind is blowing from). Applies to WIND_TYPE= 'POWER_LAW' option only, and must be input for that option. 